\title{
SEA effectiveness in Spain: insights from practice
}

\author{
Rosa M. Arce-Ruiz (D) ${ }^{a}$, Julio A. Soria-Lara ${ }^{a}$ and Ainhoa González-Del-Campo (D) ${ }^{b}$ \\ ${ }^{a}$ Centro de Investigación del Transporte (TRANSYT), Universidad Politécnica de Madrid, Madrid, Spain; 'bschool of Geography, University \\ College Dublin, Dublin, Ireland
}

\begin{abstract}
Strategic Environmental Assessment (SEA) is fairly well-established in Spain, informing decision-makers on the likely environmental consequences of their plans and policies. However, limited attention has been paid to the study of SEA effectiveness in Spain, particularly with regards to practitioner and stakeholder views. This paper aims to bridge this knowledge gap by gathering and examining views on SEA's participatory aspects, the performance of the procedural elements and the overall role of SEA in decision-making. The paper describes the legal implementation of SEA in Spain, and discusses current views on its effectiveness, grounded on the authors' own experiences.
\end{abstract}

\section{KEYWORDS}

SEA; effectiveness; stakeholder perceptions

\section{Introduction}

The overall objective of achieving high level of environmental protection is central to the Strategic Environmental Assessment (SEA) Directive (EC, 2001). However, the achievement of this objective is not always easily measurable and, hence, the performance of SEA in contributing to the goals of environmental integration into plan-making and sustainable development is often measured from various dimension, as discussed in the editorial of this Special Issue. In Spain, the effectiveness of SEA has not been formally examined to date, although a number of recent publications are starting to address relevant aspects (e.g. Pérez Gabaldón 2017; Rega et al. 2018). Moreover, the effectiveness of SEA in Spain is anticipated to significantly vary across regions. While there is an overarching legislative framework for environmental protection at the national level (Law 21/ 2013 of 9th December - Spanish Government 2013), the law is implemented by the autonomic regions with competence in environmental matters. They can establish higher protection levels, as long as they do not contradict, ignore, reduce or limit the protection established in the national legislation (STC 170/1989 of 19th October - Spanish Government 1989).

This paper aims to address the gap in current knowledge regarding the performance of SEA in Spain across the various effectiveness dimensions. In particular, it focuses on the process (e.g. procedural and pluralistic effectiveness) and its outcomes (e.g. substantive and knowledge and learning effectiveness). In doing so, it attempts, in so far as possible, to examine potential regional differences in SEA effectiveness.

\section{Strategic environmental assessment in Spain}

\subsection{National law: ordinary and simplified SEA}

Spain transposed the European SEA Directive 2001/42/ EC into national legislation through Law 9/2006 (Spanish Government 2018), which was subsequently replaced by Law 21/2013 on environmental assessment. More recently, this piece of legislation has been updated, with the introduction of Law 9/2018, but no significant changes have been made with regards to the SEA process other than strengthening the role of SEA in ensuring the protection of Natura 2000 sites.

The Spanish environmental assessment legislation defines two processes for the evaluation of plans and programmes; each to be implemented depending on the level and scope of the plan/programme, the caseby-case screening decision of the environmental authority, or by specific request of the competent authority. These processes are known as:

(1) Ordinary Strategic Environmental Assessment which is the equivalent of a common SEA in other European countries; and

(2) Simplified Strategic Environmental Assessment which applies to minor modifications of plans/ programmes that would be subject to the Ordinary SEA and to plans/programmes that establish the use of small areas at the municipal level.

In the ordinary SEA, the designated environmental authority (at the state level, the General Directorate of Environmental Quality and Evaluation of the Ministry of 


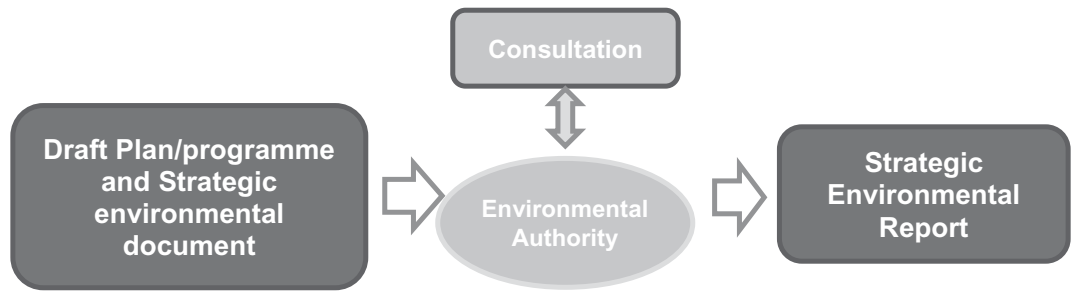

Figure 1. Simplified SEA process (based on the requirements of Law 21/2013 on Environmental Evaluation, 2019).

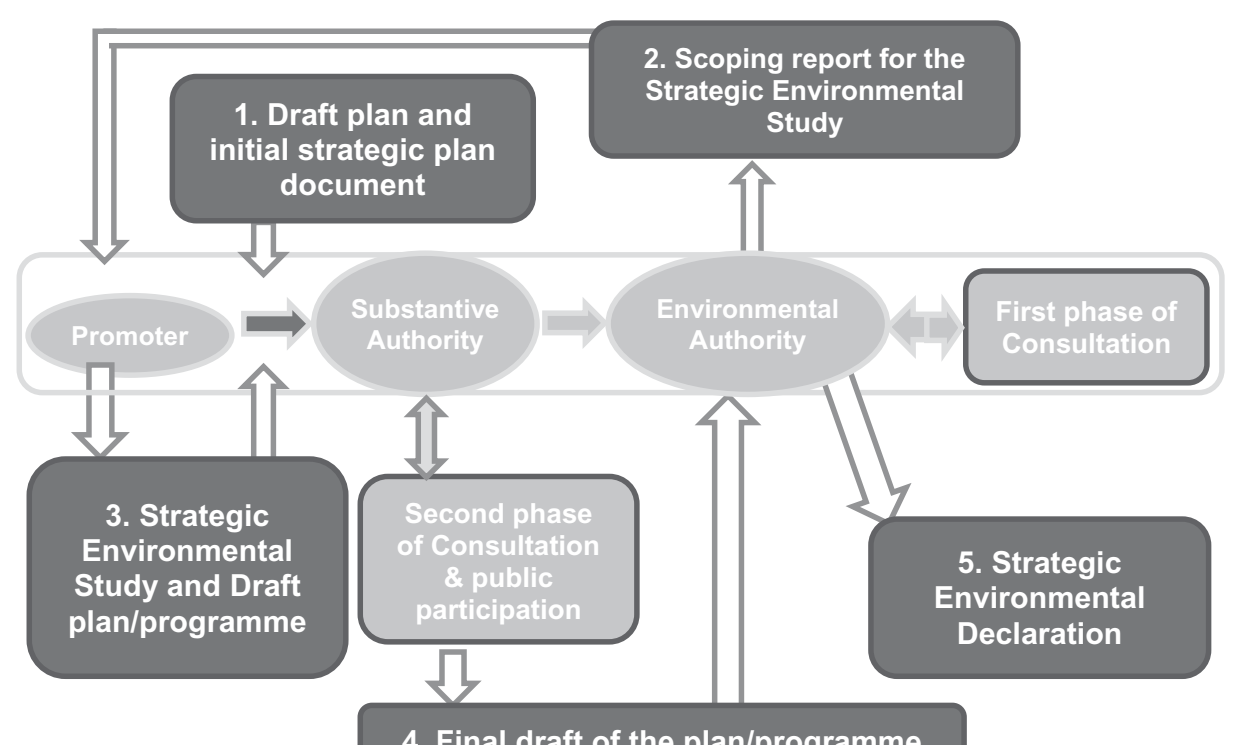

4. Final draft of the plan/programme

Figure 2. Ordinary SEA process (based on the requirements of Law 21/2013 on Environmental Evaluation, 2019).

Ecological Assessment) undertakes the preliminary consultations and prepares a scoping document for the assessment process (Figure 2 and Table 1). This document is transferred to the promoter to aid in the preparation of the Strategic Environmental Study (SES) - the equivalent to the SEA Environmental Report in other European jurisdictions, and referred to as the Environmental Sustainability Report under the original SEA transposition Law 9/2006. This SES goes to public participation and to a second (selected stakeholders) consultation phase.

Once the environmental authority receives the SES prepared by the promoter, a technical analysis of the process and of the delivered documents is undertaken and the strategic environmental declaration is issued. This declaration "will have the nature of a mandatory, determinant report, and will contain an exposition of the facts that summarize the main milestones of the procedure, including the results of public consultation (...) as well as final determinations, measures or conditions that must be incorporated into the plan or program that is finally approved or adopted" (Law 21/2013, page 28 Spanish Government 2013).

In the case of a simplified SEA, the initial request must be accompanied by the draft plan/programme and a strategic environmental document that outlines

Table 1. Differences between ordinary and simplified SEA.

\begin{tabular}{|c|c|c|c|c|c|}
\hline \multirow[b]{2}{*}{ Process } & \multicolumn{2}{|r|}{$\begin{array}{c}\text { Environmental } \\
\text { authority }\end{array}$} & \multirow[b]{2}{*}{ Substantive authority } & \multirow{2}{*}{$\begin{array}{l}\text { Assessment } \\
\text { document }\end{array}$} & \multirow{2}{*}{$\begin{array}{c}\text { Process approval } \\
\text { document }\end{array}$} \\
\hline & State & Autonomous communities & & & \\
\hline $\begin{array}{l}\text { Ordinary } \\
\text { SEA }\end{array}$ & $\begin{array}{l}\text { Dirección General } \\
\text { de Calidad } \\
\text { y Evaluación } \\
\text { Ambiental } \\
\text { Ministerio de } \\
\text { Transición }\end{array}$ & $\begin{array}{l}\text { Environmental bodies/authorities of the } \\
\text { Autonomous Communities/Regions; } \\
\text { commonly, authorities under Environmental } \\
\text { Regional Departments }\end{array}$ & $\begin{array}{l}\text { Depending on the plan, } \\
\text { sectoral Ministry or } \\
\text { regional or local } \\
\text { authorities }\end{array}$ & $\begin{array}{l}\text { Strategic } \\
\text { Environmental } \\
\text { Study }\end{array}$ & $\begin{array}{l}\text { Strategic } \\
\text { Environmental } \\
\text { Declaration } \\
\text { (Declaración } \\
\text { Ambiental } \\
\text { Estratégica) }\end{array}$ \\
\hline $\begin{array}{l}\text { Simplified } \\
\text { SEA }\end{array}$ & Ecológica & & & $\begin{array}{l}\text { Strategic } \\
\text { Environmental } \\
\text { Document }\end{array}$ & $\begin{array}{l}\text { Strategic } \\
\text { Environmental } \\
\text { Report } \\
\text { (Informe } \\
\text { Ambiental } \\
\text { Estratégico) }\end{array}$ \\
\hline
\end{tabular}


Table 3. Plans with Strategic Environmental Declaration (ordinary SEAs) and Strategic Environmental Reports (simplified SEAs) at the state level, between 2013 and 2018.

\begin{tabular}{lc}
\hline Plans with Strategic Environmental Declaration - Ordinary & \\
SEA & Number \\
\hline Hydrological and flood risk management plans & 13 \\
Operational programmes & 2 \\
National Rural Development Programme 2014-2020 & 1 \\
Spanish Marine Strategy & 1 \\
Spanish Coastal Climate Change Adaptation Strategy & 1 \\
National Waste Plan & 1 \\
European Maritime and Fishing Fund Operational Programme & 1 \\
2014-2020 & $\mathbf{2 0}$ \\
Total & \\
\hline Plans with Strategic Environmental Report - Simplified SEA & \\
Special plans for action in case of emergency and draught & 12 \\
Modifications to operational programmes & 22 \\
Motril Port Infrastructure Masterplan (Granada) & 1 \\
Plan for the Sustainable Development of Jánovas Territorial & 1 \\
$\quad$ Area & \\
Southwest Europe Cooperation Programme 2014-2020 & 1 \\
Total & $\mathbf{3 7}$ \\
\hline
\end{tabular}

the key issues (in a similar manner to a scoping report) and justifies the request for a simplified assessment process. The environmental authority then consults the affected public administrations and the interested parties/public and integrate any feedback on a Strategic Environmental Report (SER). As a result of this process, there may derive a recommendation to subject the plan to Ordinary SEA. (See Figure 2).

As in many other countries (reported by, e.g. Partidário 2000; Bina 2007; Fischer 2007; Tetlow and Hanusch 2012; Noble and Nwanekezie 2017), SEA has been implemented in Spain using the EIA philosophy. This can have significant implications in that, for example, SEAs may be utilized to assess previously drafted plans/programmes rather than functioning as a proactive tool to promote environmentally robust decisions that ultimately influence planning processes (Partidário 2000; Fischer 2003). The process can lead

Table 2. Plans published for public information at the national level, between 2006 and 2013 under Law 9/2006. There is no record of whether they were approved or not (i.e. no Environmental Report - after, under Law 21/2013, Strategic Environmental Declaration - have been made publicly available).

Environmental Sustainability Reports prepared between 2006 and 2013 under Law 9/2006 subject to public consultation

Number

Operational programmes and programmes of transboundary 33 cooperation

Airport Masterplans

Plans related to water, draught, irrigation, etc.

Harbour/port Masterplans

Energy plans

Infrastructure, transport and housing Plan (PITVI) 2012-2024

National Park Network Masterplan and Natural Heritage and Biodiversity Strategic Plan

Sustainable Rural Development Programme 2012-2014

National Integrated Waste Management Plan 2008-2015

Plan for the creation of economic activity areas associated to

Puerto Real port (Cádiz) to the elaboration of reports that are annexes to the relevant plan/programme and that have little impact in the plan/programme itself. However, effective integration of environmental considerations into the different stages of preparation of a plan/programme is also possible - and apparent in practice. Nevertheless, there is no clause or element in the Spanish law that enforces the intended environmental integration; it is the will of the planning responsible which may or may not to encourage it.

This contextual backdrop significantly influences SEA activity and practice. Between 2006 and 2013, a total of 76 SER were submitted at the national level, for public information, under Law 9/2006 (Table 2). Interestingly, the number of plan/programme SEAs decreased from 2014 onwards (Table 3), after the adoption of Law $21 / 2013$. This is possibly explained by the economic downturn rather than the reviewed legislation, as it is observed that, for example port or airport master plans that in the previous period constituted a considerable number, do not appear anymore because the number of infrastructure projects promoted has been substantially reduced.

\subsection{Regional implementation}

The implementation and effectiveness of environmental assessments is very different across the regions given that all autonomous communities/cities have published their autonomous environmental assessment laws; although it is probably more homogeneous in terms of SEA than EIA. The number of SEA processes carried out in the autonomous communities is higher than those at state level for the simple reason that environmental competencies are delegated to the regions. For example, in Andalucía, the most populated region in the country (8,405,294 inhabitants), 127 Strategic Environment Declarations and 246 SER were published from 2013 to 2018. In Madrid (6,587,711 inhabitants), only 2 SEA Statements and 255 SER have been published. In contrast, in La Rioja, the region with lowest population in Spain (312,719 inhabitants), 4 SEA Statements and 72 SER have been published. The significant differences across regions with regards to local mandates and to the number of SEAs undertaken results in varying degrees of effectiveness across the state. Legislative differences affect practice (e.g. procedural and pluralist effectiveness), and the volume of assessments are anticipated to influence experience and capacity, shaping knowledge and learning and, ultimately, substantive effectiveness.

\section{Research methodology}

To examine the effectiveness of SEA in Spain, impact assessment practitioners and experts were contacted to gather perceptions around current practice. An 
Table 4. Key questions in the online questionnaire and SEA effectiveness dimensions.

\begin{tabular}{ll}
\hline & $\begin{array}{c}\text { SEA effectiveness } \\
\text { dimension }\end{array}$ \\
\hline How would you describe the political context & Context \\
and the decision-making culture in which the & \\
SEA was carried out? & \\
What key changes to the plan did the SEA lead & Substantive \\
to? What key changes were recommended by & \\
the SEAs but not incorporated into the plan? & \\
How effective was the SEA at eliciting public & Pluralist \\
participation? & \\
How effective was the SEA at protecting the & Substantive \\
environment? & \\
How much did the SEA cost? What is the balance & Transactive \\
between benefits and costs? & \\
What is the single most important criterion for & Multi-dimensional \\
SEA to be effective? & \\
What is the most common difficulty hampering & Multi-dimensional \\
effective SEA? & \\
\hline
\end{tabular}

online questionnaire (Table 4), adapted from that suggested in the call for this Special Issue, was circulated through the Spanish Association for Environmental Impact Assessment (Asociación Española de Evaluación de Impacto Ambiental AEEIA) to its 146 members.

\section{SEA effectiveness in Spain: the experts' perceptions}

A total of 28 individuals with various SEA roles and experience participated in the online survey. While the response rate is limited (19\%) and no definite evaluation is possible from an online survey, the gathered views provide a starting point to examining SEA effectiveness in Spain, particularly in light of the current dearth of research in this area.

The majority of respondents were environmental consultants (36\%) and environmental authorities reviewing SEAs (42\%); the remainder representing local authorities commissioning SEA or stakeholders proposing changes to SEA. Most respondents declared to have been involved in more than one SEA, and a significant minority frequently acted as SEA reviewers.

When asked to think about the political context and the decision-making culture in which the SEA had been carried out, $60 \%$ of respondents declared that the evaluated plans were very 'political', while a total of $33 \%$ of participants asserted that was not the case. This may be explained by the fact that many plans represent governmental initiatives, with a clear goal to prioritise plan approval. There was unanimity between local authority representatives and stakeholders proposing changes to SEA on this 'political' bias. However, disagreement was apparent between consultants carrying out SEA and environmental authorities: $50 \%$ of the consultants and $40 \%$ of environmental authority representatives agreed that SEA is commonly 'political', with a similar percentage disagreeing with this view. This clear split is possibly an indication of the range of SEAs consultants and environmental authorities are exposed to.

Interestingly and contrastingly to the above responses, $75 \%$ of the respondents indicated that both planners and politicians were open to new information provided by the assessment and that SEA findings were taken into consideration. It is worth observing that the significant minority of consultants (40\%) disagreed with this, stating that politicians and planners are rarely open to new environmental information. While it could be argued that the positive response from environmental and local authority representatives (i.e. public administration) is indicative of an appropriate open framework for environmental integration and sustainable plan outcomes (i.e. substantive effectiveness), this is in fact questionable in light of the consultants' responses. This is further debatable given the strong dissent observed when participants were asked whether planning solutions were predetermined before undertaking the SEA: $51 \%$ of the respondents indicated that solutions were already predetermined, and $44 \%$ of ensured this was not the case. Local authority representatives and the group of stakeholders were unanimous on this, while half of consultants involved agreed and the other half disagreed. Although there is an openness that may facilitate integration, the clear divide in the responses to the predetermined planning solutions question cast doubt into the capacity of SEA to influence planning options. Given the suggested openness of plan-makers, possible explanations include a lack of coordination between SEA and planning teams, or limited capacity of the SEA team to advocate findings. In any case, the acknowledged political context of many plans plays a significant role, often leading to SEAs that tick the legal compliance boxes but are not treated as a plan improvement mechanism, thus having little impact on the plan and limited learning amongst those involved.

In the pluralist dimension, $61 \%$ of responses indicated that both the public and specific stakeholders (e.g. NGOs, professional associations, etc.) systematically engage in consultation and public participation processes. Yet few respondents indicated that SEA reports are consulted and/or used by the public to review and discuss plans during the decision-making process. More importantly, respondents suggest that public view rarely changes as a result of the assessment (Figure 3). Most respondents agreed with this view, but there was a split in the opinion amongst the stakeholder group. This could be explained by the fact that stakeholders are directly affected by public engagement efforts, resulting on a degree of dissatisfaction amongst some of them. In any case, all groups agreed that SEA is not very effective at achieving high rates of public participation. Moreover, consultants emphasised that the process is rarely effective in obtaining and integrating public information. 


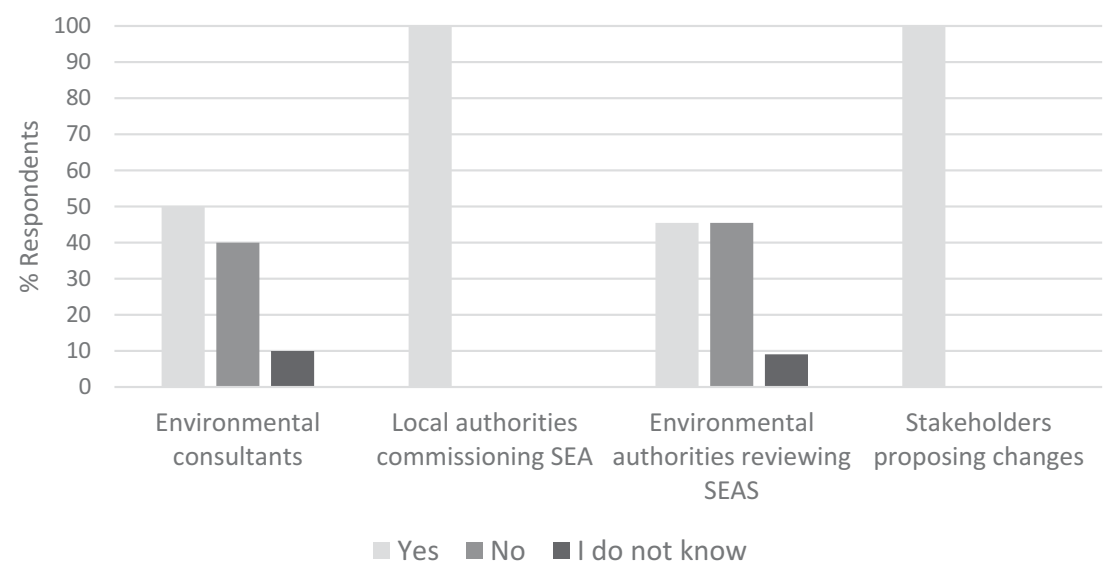

Figure 3. Groups of respondents declaring that plans evaluated by SEA were 'political'.

During the open questions, some participants observed that SEA reports were consulted by specific stakeholders (e.g. neighbourhoods or ecological associations). However, in the view of those respondents, the general public had preconceived thoughts and the SEA reports often went against such set opinions. Respondents also perceived politicians to have low capacity to alter their vision or plan goals due to SEA - which relates to the political bias of some plans discussed above. However, $50 \%$ of participants stated that planners took into account the SEA information, while $25 \%$ of respondents recognised that their view on the plan changed as a result of the SEA findings. The open ended responses pointed to plans altered by SEA, including modifications to the alternatives, and incorporation of mitigation measures in order to make planning solutions more sustainable. According to the survey respondents, only in a limited number of cases the SEA process did not incorporate significant changes into plans under evaluation. Nevertheless, it was also recognised that some proposed mitigation measures were not incorporated and that monitoring plans are hardly implemented (53\% responses). Willingness and budget constraints tend to affect implementation of mitigation and monitoring which drastically reduce the potential substantive effectiveness of the SEA process. Figure 4

$73 \%$ of respondents considered that SEA is generally effective to partly effective in providing the public with additional information (Figure 5). But a significant proportion of participants $(53 \%)$ also noticed that public views are rarely incorporated into SEA. This may be explained by the fact that SEA reports can be very technical for the general public (Soria-Lara et al. 2015). Also, the process to consult the documents may not be sufficiently disseminated, impeding an efficient access to the information from the public side. Responses to the open-ended questions indicated though, that an efficient public participation process it critical for overall SEA effectiveness. Public participation processes depend on the autonomous legislations, and variations can be found across the Spanish geography, with regards to timeframes and efforts for example, leading to significant variations in performance.

Divergent views were obtained on the perceived effectiveness of SEA to promote environmental protection (i.e. substantive effectiveness): $39 \%$ of respondents considered it did it to a large extent in the short term, $53 \%$ of them indicated that the positive effects

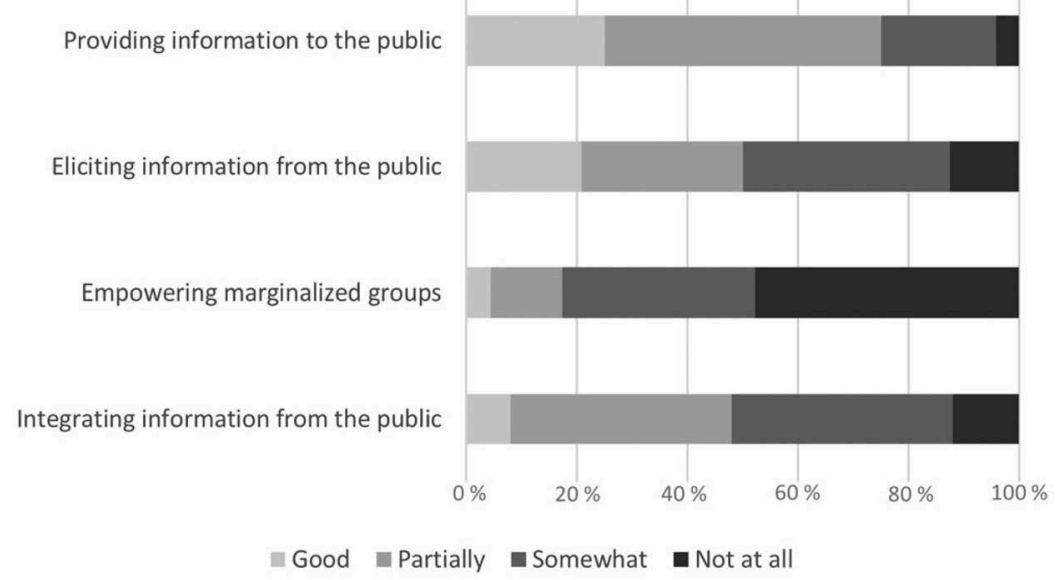

Figure 4. Survey responses on various public participation aspects of SEA. 


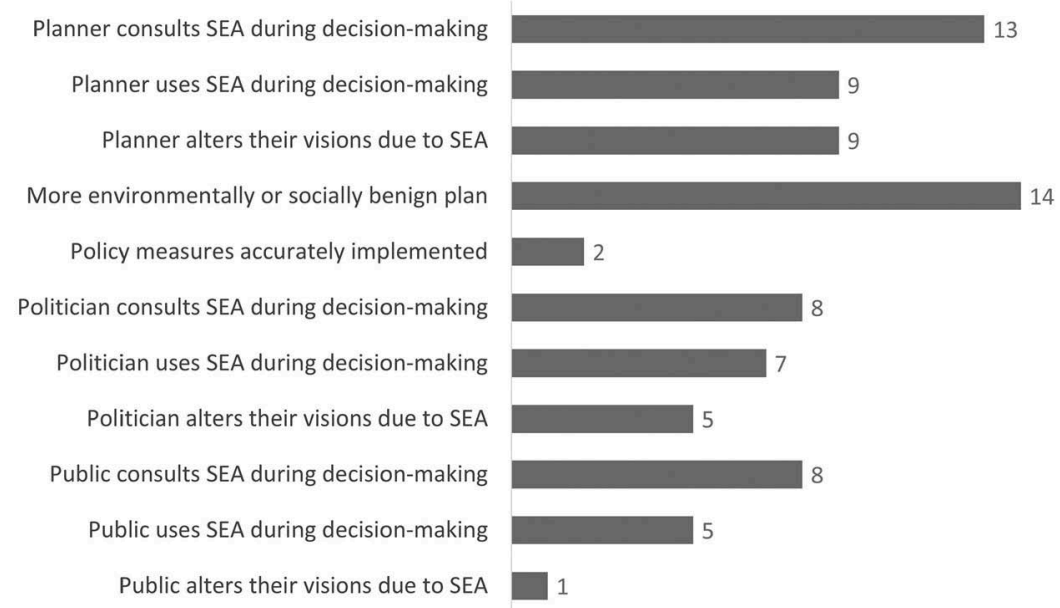

Figure 5. Survey responses on the capacity of SEA to influence plans.

of SEA are commonly manifested in the longer term. This acknowledgement of the benefits of SEA in a Spanish context has also been noted in related literature (e.g. Castro-Valencia and Arce-Ruiz 2015), and emphasised by the survey participants when answering to the transactive questions: $83 \%$ of respondents recognised that the benefits from SEA are much higher than its financial cost. The openended questions highlighted that these benefits are commonly more apparent and better materialised in local plans - rather than in national plans where the more strategic and 'elusive' content and the lack of location-based alternatives tends to render SEA less effective. Only 18 responses were received relating to SEA costs, with broad statements suggesting that SEA cost are never higher than $10 \%$ of the total cost of the plan under evaluation.

\section{Conclusions}

There was general agreement that the most influential aspect on SEA effectiveness, particularly at national level, is the willingness of policy-makers to adopt the SEA finding and recommendations. SEA legislation in Spain does not favour this integration, leaving the effective incorporation of environmental considerations to the good will of planners and SEA team's capability to work together. Given that different assessment methods and decision structures exist in the various autonomous regions, the scope (number of ordinary/simplified assessments, public engagement efforts, etc.) and effectiveness of SEA significantly vary across the country. General shortcomings are observed nevertheless with regards to the pluralist dimension: survey responses are indicative of weak participative mechanisms and limited incorporation of public feedback in current practice. Despite this, the value of SEA in shaping plans is generally recognised. The role of environmental authorities on legislative compliance is central, and the SEA's part in ensuring environmental protection and improvement is perceived as a significant added value to planning processes in Spain. Nevertheless, the effectiveness 'on paper' and the effectiveness 'on the ground' remain disconnected; current limitations on SEA follow-up, exacerbated by the scattering of authorities' responsibilities, prevent an accurate understanding of the substantive effectiveness of SEA.

To address some of the identified shortcomings, it is important to promote SEA as a learning tool between practitioners, policy-makers, and the public, providing 'dialogue spaces' where views can be modulated and strategic discussion on the environment and on future development can be carried out. This can provide a framework for institutional coordination and understanding amongst environmental authorities and stakeholders. Moreover, it could also facilitate the needed shift towards using SEA as a plan-making tool, rather than as a plan-evaluation tool - reinforcing the capacity of SEA of help the planning process. Ultimately, this would lead to better integration of SEA findings into the planning process and a clearer willingness to monitor the effects and take action.

\section{Note}

1. The resolution implies that it must be submitted to Ordinary EAE.

\section{Disclosure statement}

No potential conflict of interest was reported by the authors.

\section{ORCID}

Rosa M. Arce-Ruiz (D) http://orcid.org/0000-0001-9897-509X 
Ainhoa González-Del-Campo 9334-3066

\section{References}

Bina O. 2007. A critical review of the dominant lines of argumentation on the need for strategic environmental assessment. Environ Impact Assess Rev. 27: 585-606. doi:10.1016/j.eiar.2007.05.003

Castro-Valencia A, Arce-Ruiz RM (2015). La Evaluación Ambiental Estratégica de los planes hidrológicos en España, ciclo 2009-2015: un análisis parcial. Paper presented at the 8th National Conference on Environmental Impact Assessment (CONEIA); Mar 11-13; Madrid.

Fischer T. 2003. Strategic environmental assessment in post-modern times. Environ Impact Assess Rev. 23:155-170. doi:10.1016/S0195-9255(02)00094-X

Fischer T. 2007. Theory and practice of SEA: towards a more systemic approach. London: Earthscan. ISBN-10: 9781844074525.

Noble B, Nwanekezie K. 2017. Conceptualizing strategic environmental assessment: principles, approaches and research directions. Environ Impact Assess Rev. 62:165-173. doi:10.1016/j.eiar.2016.03.005

Partidário MR. 2000. Elements of an SEA framework: improving the added-value of SEA. Environ Impact Assess Rev. 20:647-663. doi:10.1016/S0195-9255(00)00069-X

Pérez Gabaldón M. 2017. Strategic environmental assessment as an instrument for environmental protection: Comunidad
Valenciana as a case study. J Public Program Policy Eval. 8:31-53. doi:10.5944/reppp.8.2017.16319

Rega C, Singer JP, Geneletti D. 2018. Investigating the substantive effectiveness of strategic environmental assessment of urban planning: evidence from Italy and Spain. Environ Impact Assess Rev. 73:60-69. doi:10.1016/j.eiar.2018.07.004

Soria-Lara JA, Bertolini L, Te Brömmelstroet M. 2015. Environmental impact assessment in urban transport planning: exploring process-related barriers in Spanish practice. Environ Impact Assess Rev. 50:95-104. doi:10.1016/j.eiar.2014.09.001

Spanish Government. 1989. STC 170/1989 of 19th October. Boletín Oficial del Estado - BOE núm. 267, of 7th of November of 1989.

Spanish Government. 2013. Law 21/2013 of 9th December, Ley $21 / 2013$, de 9 de diciembre, de evaluación ambiental. Boletín Oficial del Estado BOE núm. 296, of 11th December 2013.

Spanish Government. 2018. Ley 9/2018, de 5 de diciembre, por la que se modifica la Ley 21/2013, de 9 de diciembre, de evaluación ambiental, la Ley 21/2015, de 20 de julio, por la que se modifica la Ley 43/2003, de 21 de noviembre, de Montes y la Ley $1 / 2005$, de 9 de marzo, por la que se regula el régimen del comercio de derechos de emisión de gases de efecto invernadero. Boletín Oficial del Estado - BOE núm. 294, of 6th December 2018.

Tetlow M, Hanusch M. 2012. Strategic environmental assessment: the state of the art. Impact Assess Project Appraisal. 30(1):15-24. doi:10.1080/14615517.2012.666400 